\title{
APRENDIZAGEM DA EXTENSÃO DA PROBÓSCIDE EM ZANGÕES AFRICANIZADOS (Apis mellifera L.) CONFINADOS
}

\author{
LEARNING OF PROBOSCIS EXTENSION IN HARNESSED \\ AFRICANIZED HONEY BEE DRONES (Apis mellifera L.)
}

Italo de Souza Aquino ${ }^{1}$

Maurizete Cruz Silva ${ }^{2}$

Alex da Silva Barbosa ${ }^{3}$

Charles Ira Abramson 4

${ }_{1}^{1}$ Professor Doutor da Universidade Federal da Paraíba (UFPB), Laboratório Apícola (LA), Bananeiras, PB, Brasil italo.aquino@pesquisador.cnpq.br

2Professora do Colégio Agrícola Vidal de Negreiros (CAVN), Bananeiras, PB, Brasil

${ }^{3}$ Professor do Colégio Agrícola Vidal de Negreiros (CAVN), Bananeiras, PB, Brasil

${ }^{4}$ Professor da Oklahoma State University, Stillwater, OK, EUA

\section{Resumo:}

Estudos sobre a aprendizagem olfativa em abelhas (Apis mellifera L.) são predominantes nas operárias. Neste estudo, utilizou-se o condicionamento clássico da extensão da probóscide (PER) para avaliar o efeito de 5 odores como estímulos condicionantes (EC). Foram utilizados dez grupos de 20 zangões (A. mellifera L.) cada. Os estímulos condicionantes foram Citral, Hexanal, Geraniol, cera de abelha em favo e cera de abelha alveolada. Além da aquisição de aprendizagem, mediu-se a persistência do condicionamento quando o estímulo incondicional (EI) não foi mais oferecido (i.e. extinção). O intervalo entre testes, o tempo de apresentação de EC e EI foram10 minutos, 2 segundos e 3 segundos, respectivamente. Os zangões foram capazes de demonstrar condicionamento e armazenamento de informação. Citral, Hexanal e cera de abelha foram os estímulos mais eficientes no condicionamento clássico (CC) com zangões.

Palavras-chave: abelhas; condicionamento clássico; odores.

\begin{abstract}
:
Studies on the olfactive learning in honey bees (Apis mellifera L.) are predominantly performed with worker bees. In this study, we used the classical conditioning of proboscis extension (PER) to evaluate the effectiveness of 5 scents as conditioned stimuli (CS). Ten groups of 20 drones ( $A$. mellifera L.) each were used. The conditioned stimuli were the odors of Citral, Hexanal, Geraniol, beeswax (comb), and beeswax (foundation sheet). In addition to the acquisition of learning, we measured the persistence of conditioning when the unconditioned stimulus was no longer presented (i.e., extinction). The intertrial interval, the CS duration and US duration were $10 \mathrm{~min}, 2 \mathrm{sec}$, and 3 sec, respectively. The drones were able to demonstrate conditioning and storage of information.
\end{abstract}


Citral, Hexanal, and beeswax (comb) were the most efficient stimuli in classical conditioning with drones.

Keywords: bees; classical conditioning; odors.

Recebido em: 16 fev. 2013.

Aceito em: 07 out. 2014

\section{Introdução}

A aprendizagem associativa com abelhas é um processo rápido e tenaz em que a memória, uma vez induzida por um teste único de aprendizagem, pode durar alguns dias ${ }^{(1)}$. A aplicação prática do condicionamento clássico requer frequentemente um levantamento de eventos que reforçam o indivíduo. O reforço, neste caso, nada mais é do que o pareamento de um dado estímulo. É possível demonstrar o reforço condicionando mais rapidamente com estímulos que possam ser controlados. Os eventos observados que servem de reforçadores são de dois tipos: 1) apresentação de alguma coisa, como por exemplo: alimento (água), que por sua vez é denominado de reforço positivo; 2) remoção de alguma coisa, como por exemplo: luz muito brilhante, calor ou frio extremos ou, ainda, um choque elétrico, que se denominam reforços negativos. Assim, para se avaliar a extensão total da mudança ocasionada pelo reforço, é preciso investigar os efeitos de um grande número de estímulos.

Estudos de condicionamento clássico (CC) em abelhas são predominantes com operárias, tanto em experimentos em laboratório ${ }^{(2,3)}$, como em testes em campo ${ }^{(4-6)}$. Em relação a aspectos práticos de CC em zangões, destaca-se a relevante contribuição de Silva et al. ${ }^{(7)}$, no uso destes na detecção de cera de abelha adulterada. A íntima relação da abelha com a cera durante toda a sua vida na colmeia a torna um potente estímulo em estudos de CC.

Nesse contexto, a cera (alveolada e favo) constitui-se em um elemento com grande potencial para fazer parte do rol dos estímulos olfativos mais utilizados (Hexanal, Citral e Geraniol) em experimentos de condicionamento da probóscide com abelhas (europeias e africanizadas). $\mathrm{O}$ propósito desses experimentos, portanto, é prover dados sobre o condicionamento clássico da extensão da probóscide (PER) em zangões de abelhas africanizadas (Apis mellifera L.). No procedimento de PER, um estímulo olfatório (conhecido como estímulo condicionante EC) é pareado com a alimentação de sacarose (conhecido como estímulo incondicionante EI) e, depois de vários pareamentos EC-EI, a probóscide é estendida durante a apresentação do EC, porém antes da aplicação do EI. O paradigma PER tem se tornado padrão na análise de aprendizado em abelhas ${ }^{(1)}$ embora, recentemente, problemas com o procedimento tenham sido reportados ${ }^{(8,9)}$.

A análise racional por trás desse experimento é dupla. Primeiro, objetivou-se completar a análise comparativa do aprendizado em abelhas africanizadas. Em experimentos anteriores realizados no LA/UFPB com abelhas operárias constatou-se a primeira evidência de condicionamento clássico e aprendizado discriminativo em abelhas operárias africanizadas $[\mathrm{AOA}]^{(2)} \mathrm{e}$, mais interessante, sugeriu-se que possa existir uma diferença entre subespécies na habilidade de aprendizagem entre AOA e abelhas operárias europeias [AOE]. Essa sugestão recentemente recebeu apoio de um laboratório independente que também encontrou que $\mathrm{AOA}$ aprendem "menos" que $\mathrm{AOE}^{(10)}$. O 
mesmo laboratório deste estudo também proveu dados demonstrando que a rainha de AOA podem também aprender a associar um EC e EI usando o paradigma PER ${ }^{(9)}$.

Existem poucos estudos sobre o aprendizado de zangões de abelhas europeias [ZAEs] e são embrionários os estudos com zangões de abelhas africanizadas [ZAAs]; destacam-se, apenas, os trabalhos sobre a habilidade de zangões africanizados em detectar cera de abelha adulterada ${ }^{(7)}$ e acerca do comportamento nutricional de zangões (africanizados) em diferentes tempos de jejum ${ }^{(10)}$. Os estudos sobre zangões europeus foram desenhados para examinar a hereditariedade de condicionamento em abelhas operárias e proveram evidências convincentes que zangões podem aprender $^{(11-13)}$. Recentemente, usando-se a técnica de condicionamento aversivo em que zangões são confinados em uma caixa de transporte ${ }^{(14)}$, relatou-se que, em tarefas de escape e punição, abelhas operárias superam zangões. Esse experimento é único em que ambos zangões e operárias foram testados sob os mesmos protocolos experimentais e condições ambientais.

O segundo raciocínio por trás desses experimentos é que ele prepara o "palco" para o estudo da relação entre a sociabilidade e a aprendizagem entre as abelhas africanizadas. As abelhas operárias (fêmeas) são altamente sociais em contraste com os zangões (machos) que são mais "solitários". Evidências têm demonstrado que existe uma correlação positiva entre o papel sóciocomportamental e mudanças na arquitetura do cérebro ${ }^{(15)}$. A arquitetura do cérebro é influenciada pela idade, tarefa e experiência. Plasticidade socialmente mediada pela corpora pedunculata (CP) de fêmeas têm sido observada na transição induzida por idade a partir de tarefas dentro da colônia por abelhas nutrizes para tarefas mais complexas como forrageamento ${ }^{(16)}$. Mudanças semelhantes na $\mathrm{CP}$ têm sido observadas em machos à medida que eles começam seus voos de orientação e acasalamento $^{17}$. Todos os trabalhos até então relatados têm sido com abelhas europeias. O estudo de sociabilidade e aprendizado em abelhas africanizadas não pode ser feito até que a amplitude do aprendizado em zangões (africanizados) seja conhecida.

O propósito deste trabalho, portanto, foi investigar a eficácia de aquisição destes distintos estímulos condicionantes em zangões (A. mellifera L.) adultos e verificar se zangões com um dia de vida têm a habilidade de aprender.

\section{Material e Métodos}

Este estudo foi realizado no Laboratório Apícola (LA) da Universidade Federal da Paraíba (UFPB), Campus III. Foram capturados 320 zangões africanizados (Apis mellifera L.) [200, Experimento 1; 120, Experimento 2] no apiário pertencente ao LA da UFPB.

Os zangões foram coletados do interior da colmeia às 15:00h do dia anterior aos testes. Utilizaramse tubos de metal (3,5 cm x 1,0 cm de diâmetro), feitos com antena de TV, para acondicionamento dos zangões. Cada zangão foi colocado individualmente em cada tubo; utilizou-se fita adesiva (Duct Tape - Scotch ${ }^{\mathrm{TM}}$ ) com $3 \mathrm{~mm}$ de espessura para segurar cada animal na região entre a cabeça e o tórax. Os zangões foram alimentados com solução de sacarose (1:1) através de fitas de papel filtro embebidas da solução, até o saciamento. Os testes foram realizados a partir das $6 \mathrm{~h} 30 \mathrm{~m}$ da manhã seguinte. Para o uso da cera de abelha em favo e cera de abelha alveolada como ECs, estas foram colocadas previamente dentro de seringas plásticas de 20cc dias antes ao uso para se obter uma melhor concentração do odor no interior da seringa. 
No Experimento 1, realizado com zangões adultos, os indivíduos foram divididos em 10 grupos com 20 indivíduos cada. Para os animais dos grupos 1-5, os ECs consistiram de Geraniol (Sigma ${ }^{\circledR}$, produto químico número G-5135), Hexanal (Sigma ${ }^{\circledR}$, produto químico número H-9008), Citral $\left(\right.$ Sigma $^{\circledR}$, produto químico número C-1645), odor de cera de abelha em favo e, também, odor de cera de abelha alveolada, respectivamente. Cada um dos 5 grupos pareados teve um grupo controle não pareado (grupos 6-10). Os animais do grupo pareado receberam 12 tentativas pareadas de EC, seguido por 12 tentativas de extinção em que o EI era omitido. O propósito das tentativas de extinção foi determinar se a persistência estaria relacionada ao tipo de EC utilizado no treinamento. Os intervalos entre teste, de EC-EI e a duração do EI foram: 10 min, 2s e 3s, respectivamente. Os animais dos grupos não pareados receberam apresentações de EC-EI usando-se a sequência contrabalanceada: EC EI EI EC EI EC EC EI EC EI EI EC EI EC EC EI EC EI EI EC EI EC EC EI; o intervalo entre tentativas foi de $5 \mathrm{~min}$ e a duração do EC e a duração do EI foi de 2 e $3 \mathrm{~s}$, respectivamente, segundo metodologia de ABRAMSON et al. ${ }^{(2)}$. Os animais foram colocados em pelotões, sendo que cada qual continha animais para 10 grupos. A coleta de dados terminou quando cada indivíduo recebeu 20 apresentações. A probabilidade resposta [P(REP)] foi calculada na forma padrão:

$$
\mathrm{P}(\mathrm{REP})=\frac{\text { Número de abelhas respondendo }}{\text { Número de abelhas do teste }}
$$

A análise de variância (ANOVA) foi efetuada para as variáveis tentativas, grupo, estímulo, aquisição e extinção.

No Experimento 2, os zangões tinham um dia de vida. Foram coletados quadros de ninho com células operculadas de zangões em fase de emergência das colmeias do LA/UFPB. Esses favos foram colocados em uma colmeia de vidro e conduzidos para o interior do LA. Para este teste foram utilizados 120 zangões com um dia de vida e 120 adultos.

Os mesmos instrumentos do Experimento 1 foram utilizados, acrescentando-se uma colmeia de vidro para observação do momento exato do nascimento dos zangões.

Os zangões foram selecionados imediatamente após a emergência das células. Estes foram acondicionados em tubos de metal e divididos em três grupos distintos, contendo 20 indivíduos cada, e treinados usando-se o mesmo método já descrito no experimento anterior. Os estímulos condicionados foram: Hexanal, cera de abelha e água (estímulo da antena). Quanto ao estímulo da antena, este foi incluído para promover um EC qualitativamente diferente dos demais odores e por já ter sido testado com abelhas operárias. Para cada grupo pareado foi usado um grupo não-pareado como testemunha. Para todos os grupos foram realizadas 12 tentativas de aquisição e 12 de extinção. O EI usado foi uma solução de mel (1:1), por 2 segundos, com intervalo entre teste de 10 minutos.

\section{Resultados e Discussão}

No Experimento 1, observou-se que, quando o EI foi omitido durante a extinção, a resposta dos animais aos ECs de Geraniol, cera em favo e cera alveolada declinou (Figura 1); já para o Citral e Hexanal não houve declínio. Abramson et al. ${ }^{(2)}$, expondo abelhas operárias africanizadas a estas mesmas condições experimentais, verificaram que as abelhas apresentaram aquisição quando os 
ECs e EIs são devidamente pareados e, após omissão do EI (fase de extinção), estas vão reduzindo as respostas ao EC gradativamente. A ANOVA produziu efeito significativo de Tentativas $\mathrm{F}(3,24)$, $\mathrm{p}=0,000$. Houve, também, efeito significativo quando da interação Grupo vs. Estímulo $\mathrm{F}(20,8672)$, $\mathrm{p}=0,000$. ANOVAs separadas foram realizadas para comparar a fase de Aquisição vs. Extinção. Estas revelaram efeito significativo para a fase entre os estímulos condicionados de Citral $\mathrm{F}(14,1997), \mathrm{p}=0,000$; Hexanal $\mathrm{F}(8,1163), \mathrm{p}=0,05$; cera em favo $\mathrm{F}(5,5659), \mathrm{p}=0,020$ e cera alveolada $\mathrm{F}(10,1042), \mathrm{p}=0,002$. Já para o $\mathrm{EC}$ de Geraniol não houve efeito significativo $\mathrm{F}(0,3593), \mathrm{p}=0,550$. A aquisição apresentou-se melhor para os odores de Citral, Hexanal, cera em favo e cera alveolada. Observou-se que, durante a fase de extinção, a taxa de declínio caiu em 3 dos 5 grupos. Os ECs de Hexanal e Citral não mostraram declínio. O Geraniol, todavia, apresentou declínio mais rápido do que a cera favo e a cera alveolada. O comportamento durante a fase de extinção é o resultado do condicionamento que o antecedeu e, desta forma, a curva de extinção revela o efeito do reforço. Smith e Menzel ${ }^{(17)}$ e Bhagavan e Smith $^{(18)}$ consideram a resposta condicionada dependente dos estímulos (odores) usados no condicionamento, os quais podem elucidar uma resposta apetitiva muito mais intensa do que outros quando submetidos a um processo semelhante de condicionamento. Respostas semelhantes já foram encontradas em abelhas operárias europeias ${ }^{(19)}$, as quais demonstraram respostas distintas a vários odores.

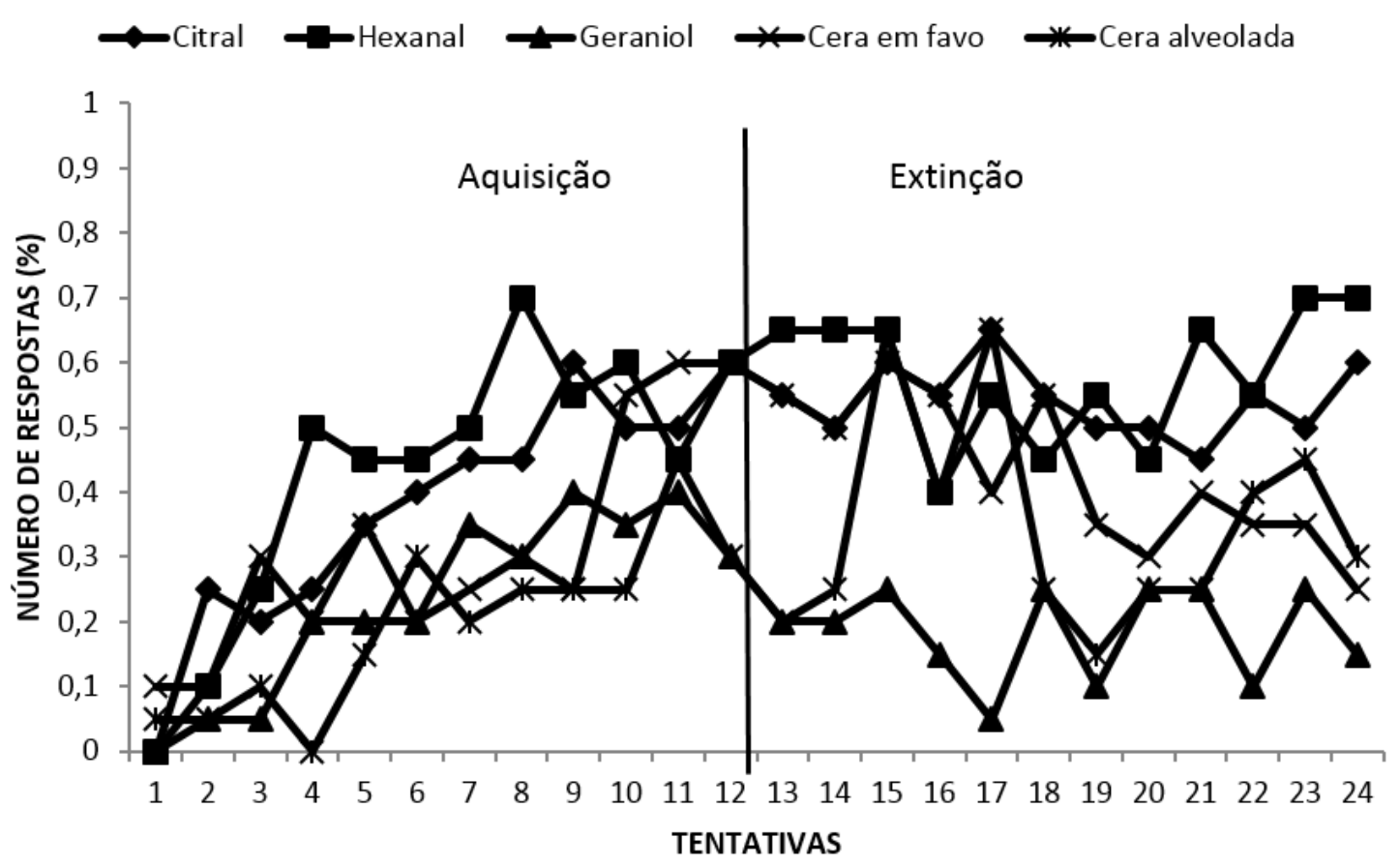

Figura 1: Proporções médias de zangões (Apis mellifera L.) respondendo aos vários ECs (citral, hexanal, geraniol, cera em favo e cera alveolada) durante testes de aquisição (tentativas 1 a 12) e extinção (tentativas 13 a 14).

Os resultados do experimento 1 mostram que zangões adultos confinados podem aprender a associar a EC e EI, porém a força do relacionamento é influenciada pelo tipo de EC usado. O melhor desempenho obtido foi com o EC de Citral e Hexanal e o pior EC foi o de cera alveolada, cera em favo e Geraniol (Figura 1). O desempenho de zangões africanizados adultos em situações de PER são contrastantes com a de zangões europeus adultos. Pesquisas ${ }^{(11-12,20)}$ mostram 
aprendizado robusto semelhantes aos demonstrados por operárias europeias; todavia, em situações de condicionamento aversivo, operárias superam zangões ${ }^{(14)}$.

O nível assintótico do desempenho de zangões africanizados é semelhante ao encontrado em abelhas operárias africanizadas ${ }^{(2,8)}$ raramente alcançam $70 \%$ da amostragem de aprendizado em situações de PER. Não é conhecido o que zangões africanizados fariam em situações de condicionamento aversivo tais como escape, punição e retirada ${ }^{(10)}$. É interessante observar que o desempenho de abelhas rainhas africanizadas é semelhante ao de operárias e zangões europeus. A maioria das abelhas rainhas africanizadas demonstraram aprendizado na associação de EC com alimento $^{(9)}$. É óbvia a necessidade de se realizarem mais pesquisas com zangões africanizados. Por exemplo, seria de grande interesse a condução de uma variedade de experimentos com zangões africanizados nos tópicos de aprendizado discriminatório, aprendizado inibitório e condicionamento aversivo. Tais estudos colocariam o fundamento para estudos analíticos sobre a relação entre sociabilidade e aprendizado em abelhas africanizadas.

No Experimento 2, observou-se que zangões com um dia de vida exibiram um certo aprendizado (Figura 2), mas cerca de $40 \%$ dos zangões responderam à cera em favo logo na primeira apresentação (mesmo antes de ser pareado com um EI). Além disso, à medida que o treino progrediu, o número de respostas ao EC decresceu. Tal padrão de respostas sugere que não há aprendizado, mas, ao invés disso, zangões com um dia de vida são sensibilizados pelo odor da cera em favo e ao longo do curso das repetidas apresentações habituaram com a sua presença.

\section{Cera em favo}

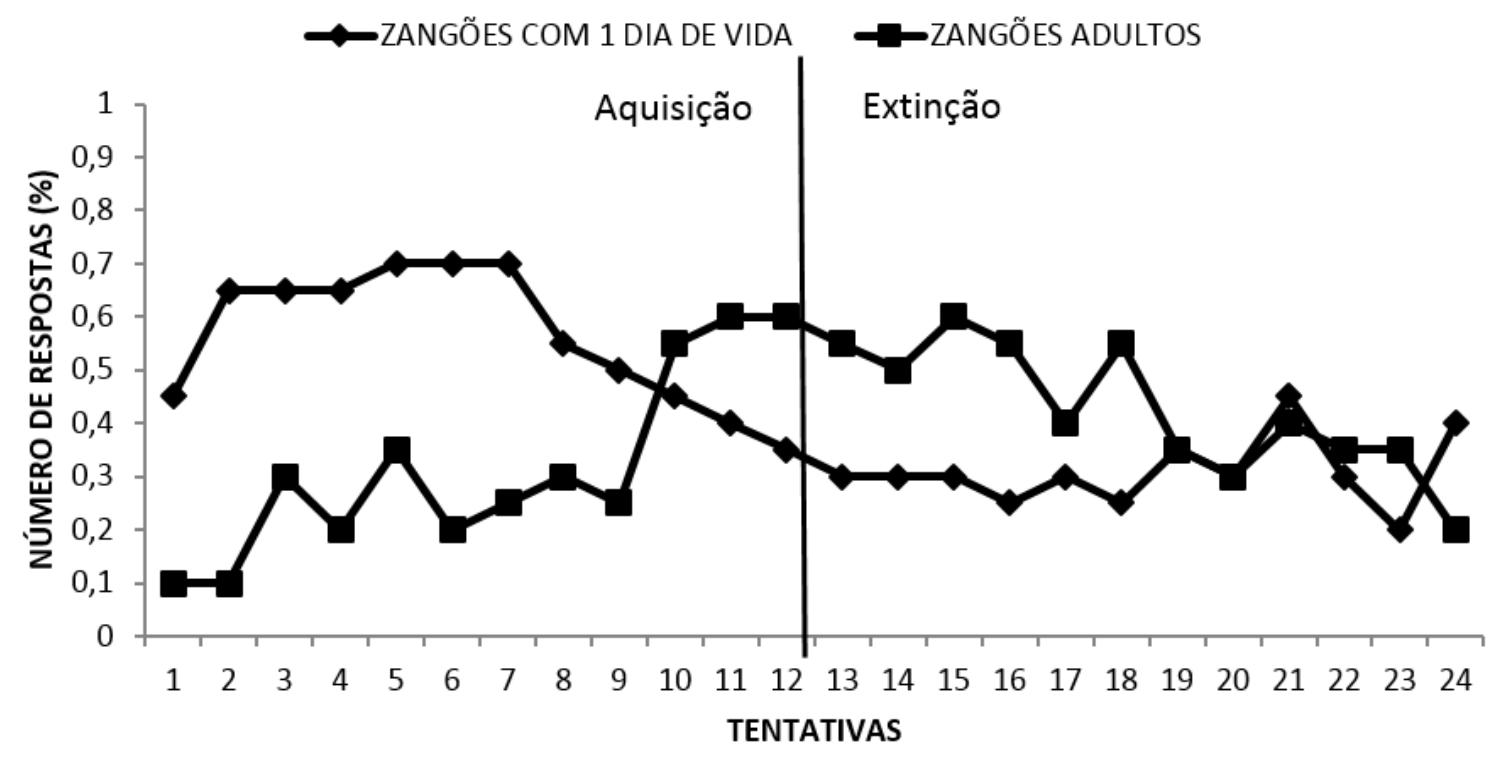

Figura 2: Proporção de animais (zangões com um dia de vida versus zangões adultos) respondendo a 12 treinos pareados de EC-EI, durante 12 tentativas de aquisição e 12 de extinção. A prova de extinção ocorreu a partir da $13^{\mathrm{a}}$ tentativa, em que o EI foi omitido (EC: cera em favo). 


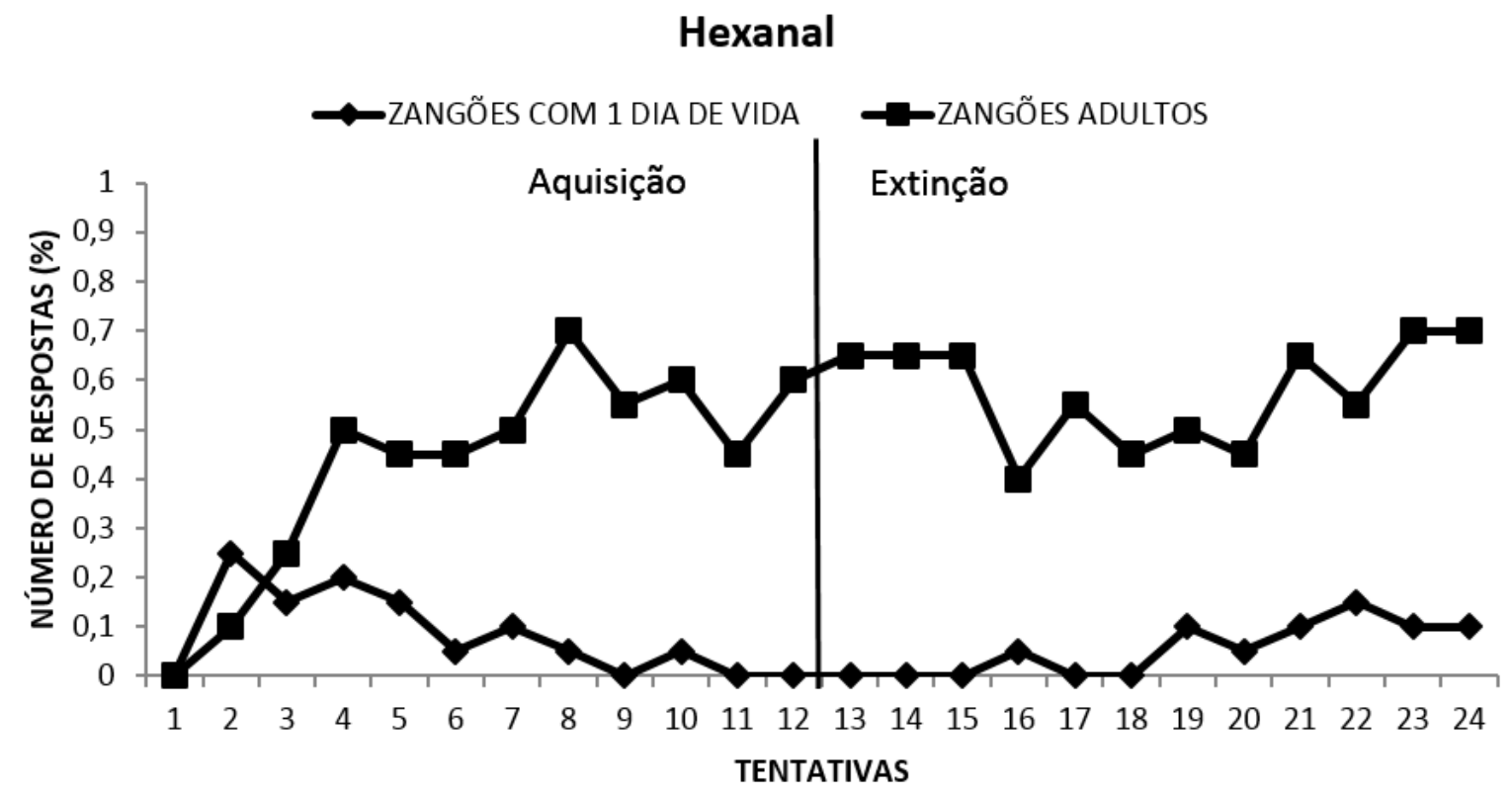

Figura 3: Proporção de animais (zangões com um dia de vida versus zangões adultos) respondendo a 12 treinos pareados de EC-EI, durante 12 tentativas de aquisição e 12 de extinção. A prova de extinção ocorreu a partir da $13^{\mathrm{a}}$ tentativa, em que o EI foi omitido (EC: hexanal).

Quando oferecidos Hexanal como EC, os zangões com um dia de vida não mostraram aprendizagem (Figura 3). Entretanto, quando os animais receberam estímulo com água (na antena), houve um desempenho surpreendentemente melhor que os outros estímulos, demonstrando uma performance gradativa de aprendizagem em $85 \%$ (Figura 4). A ANOVA revelou, contudo, não haver diferenças entre os grupos, os quais não apresentaram diferenças significativas produzindo $\mathrm{F}(0.0016), \mathrm{p}=0.698$. Também não verificou-se diferença para a interação Tratamento vs. Grupo $\mathrm{F}(0.2573)$, mas observou-se haver diferenças significativas para Tratamento com $\mathrm{F}(16.0426) \mathrm{p}=$ 0.000 .

Os resultados desses experimentos com zangões africanizados sugerem que eles podem aprender uma simples associação entre um odor e alimento e isso é consistente com pesquisas prévias com zangões não-africanizados ${ }^{(12)}$. Deve ser observado, contudo, que as curvas de aprendizado de zangões africanizados são, em geral, mais baixas que as encontradas para zangões nãoafricanizados, dados consistentes com as baixas curvas de aprendizado encontradas com abelhas operárias africanizadas $^{(8)}$. Se tal diferença entre os zangões africanizados e não-africanizados revela uma diferença de subespécie isso só pode ser determinado através de experiências comparativas sob as mesmas condições ambientais e experimentais. Também é interessante notar que nem todos os estímulos condicionados usados em nossos experimentos produziram bom condicionamento. No Experimento 1, Hexanal e Citral produziram resultados estáveis, mas Geraniol, cera em favo ou alveolada, quando usados como estímulos condicionantes, não. Os resultados com Hexanal foram replicadas no Experimento 2 (Figura 3). 


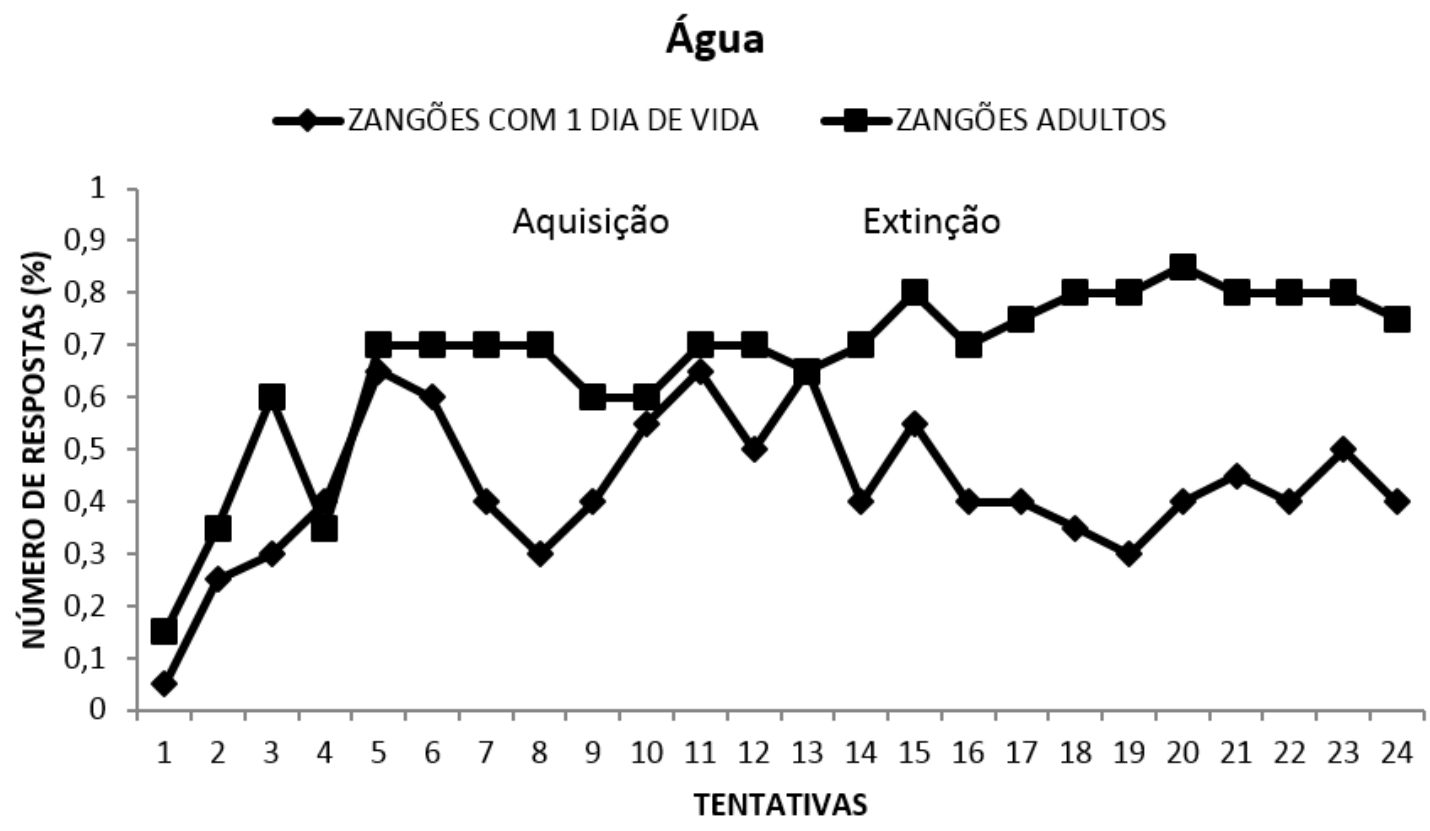

Figura 4: Proporção de animais (zangões com um dia de vida versus zangões adultos) respondendo a 12 treinos pareados de EC-EI, durante 12 tentativas de aquisição e 12 de extinção. A prova de extinção ocorreu a partir da $13^{\mathrm{a}}$ tentativa, onde o EI foi omitido (EC: água).

Os experimentos com o aprendizado de zangões com um dia de vida são ambíguos. Dos estímulos condicionados testados, apenas a estimulação de água na antena forneceu alguma evidência para a aprendizagem e, mesmo assim, o desempenho foi instável. Em contrapartida, o desempenho de zangões adultos foi consistente com a interpretação de aprendizagem. Quando zangões com um dia de vida e zangões adultos foram expostos a um estímulo condicionado de cera em favo, houve alguma melhora para os zangões com um dia de vida nas tentativas 1 e 2. Porém, deve ser observado que quase metade dos zangões com um dia de vida responderam à cera em favo antes de qualquer pareamento com um EI. Além disso, à medida que as tentativas de treinamento com cera em favo progrediram, os zangões com um dia de vida tornaram-se menos sensíveis ao contrário dos zangões adultos que aumentaram suas respostas aos ECs com o progresso dos treinamentos. Em muitos aspectos, as curvas dos zangões com um dia de vida sugerem que eles estão habituando-se ou adaptando-se ao odor da cera em favo. O fraco desempenho de zangões com um dia de vida ao Hexanal (Figura 3) é semelhante ao que foi observado no trabalho anterior com abelhas operárias com um dia de vida ${ }^{(21)}$.

O estudo do comportamento adaptativo de zangões africanizados está apenas começando. Claramente, mais estudos precisam ser realizados utilizando-se diferentes paradigmas e diferentes estímulos. Recentemente, a confiabilidade do paradigma de condicionamento da probóscide tem sido questionada ${ }^{(9,10)}$ e isto levou ao desenvolvimento de novos paradigmas. Um dos mais novos paradigmas utilizados com zangões é o condicionamento aversivo em que estímulos aversivos, como choque é usado ao invés de estímulos apetitivos para estudar fuga, punição e anulação de aprendizagem $^{(14)}$. A aplicação de novos paradigmas de aprendizagem para o estudo do comportamento zangão é esperado para fornecer novos entendimentos. 


\section{Conclusões}

Os resultados desta pesquisa com zangões africanizados (Apis mellifera L.) submetidos a testes de PER, permitem concluir que zangões são capazes de demonstrar condicionamento e armazenagem de informação quando submetidos a diferentes estímulos condicionantes em testes de condicionamento clássico (CC); odores de Citral, Hexanal e cera de abelha em favo podem ser usados como EC em CC com zangões; o desempenho de zangões com um dia de vida é pobre (aprendizagem instável) em relação a zangões adultos quando o EC é 'toque nas antenas com água'; e condicionamento não foi demonstrado em zangões com um dia de vida quando se utilizou Hexanal com EC, diferentemente do que ocorre em zangões adultos usando o mesmo odor.

\section{Agradecimentos}

Ao Técnico em Agropecuária Francisco Nogueira da Silva pelo acompanhamento durante a captura das abelhas no Apiário pertencente ao Laboratório Apícola da Universidade Federal da Paraíba.

\section{Referências}

1 Hammer M, Menzel R. Learning and memory in the honey bee. Journal Neuroscience. 1995; 15(3): 1617 1630. Disponível em: http://www.jneurosci.org/content/15/3/1617.full.pdf. Acesso em 15 janeiro de 2015.

2 Abramson CI, Aquino IS, Silva MC, Price JM. Learning in the africanized honey bee: Apis mellifera L. Physiology \& Behavior. 1997a; 62(3): 657-674. http://dx.doi.org/10.1016/S0031-9384(97)00194-7.

3 Abramson CI, Aquino IS, Azeredo GA, Price JM. Some preliminary studies on the ability of Africanizaed honey bees (Apis mellifera L.) to tolerate cold temperatures when placed inside a refrigerator. Psychological Reports. $1997 b ; 1$ 81(Dec.): 707-718. https://www.google.com.br/url?sa=t\&rct=j\&q=\&esrc=s\&source=web\&cd=1\&cad=rja\&uact=8\&ved=0CB0 QFjAA\&url=http\%3A\%2F\%2Fwww.gvaa.com.br\%2Frevista\%2Findex.php\%2FRVADS\%2Farticle\%2Fdo wnload\%2F1848\%2F1748\&ei=GtfEVJuEGsKdNpfKgYAK\&usg=AFQjCNGyjLGrpH1dOI9JhFGIc_LiWT QW8Q\&sig2=Yn4Be_aYystI66O70vKrIw\&bvm=bv.84349003,d.eXY. Acesso em 15 janeiro de 2015.

4 Grüter C, Arenas A, Farina WM. Does pollen function as a reward for honeybees in associative learning? (Apis mellifera)? Insectes Sociaux. 2008; 55(4): 425-427. Disponível em: http://www.socialinsectresearch.com/resources/Gr\%C3\%BCteretal.2008b.pdf. Acesso em 15 janeiro de 2015.

5 Fernández V, Arenas A, Farina WM. Passive volatile exposure within the honeybee hive and its effect on odor discrimination. Journal of Comparative Physiology. 2009; 195: 759-768. Disponível em: http://link.springer.com/article/10.1007/s00359-009-0453-4. Acesso en 15 janeiro 2015

6 Arenas A, Farina WM. Learned olfactory cues affect pollen-foraging preferences in honeybees. Animal Behaviour. 2012; 83(4): 1023-1033. http://dx.doi.org/10.1016/j.anbehav.2012.01.026

7 Silva MC, Aquino IS, Abramson CI, Santos JW. Uso de zangões (Apis mellifera L.) na detecção de cera de abelha adulterada. Brazilian Journal of Veterinary Reseach and Animal Science. 2000; 37(6). http://dx.doi.org/10.1590/S1413-95962000000600015.

8 Aquino IS, Silva MC, Aquino IS, Barbosa AS. Estudo do comportamento nutricional dos zangões (Apis mellifera L.) após diferentes tempos de jejum. Revista Verde de Agroecologia e Desenvolvimento Sustentável. 2013; 8(2): 41-44. Disponível em: http://www.gvaa.com.br/revista/index.php/RVADS/article/view/1848/pdf_736. Acesso em 15 janeiro 2015. 
9 Aquino IS, Abramson CI, Soares AE, Fernandez AC, Benbassat D. Classical conditioning of proboscis extension in harnessed Africanized honey bee queens (Apis mellifera L.) Psychological Reports. 2004; 94: 1163-1174. http://dx.doi.org/10.2466/pr0.94.3c.1221-1231

10 Couvillon MJ, Degrandi-Hoffman G, Gronenberg W. Africanized honeybees are slower learners than their European counterparts. Naturwissenschaften. 2010; 97: 153-160. Disponível em: http://link.springer.com/article/10.1007\%2Fs00114-009-0621-y. Acesso em 15 janeiro 2015.

11 Benatar ST, Cobey S, Smith BH. Selection on a haploid genotype for discrimination learning performance: correlation between drone honey bees (Apis mellifera) and their worker progeny (Hymenoptera: Apidae). Journal of Insect Behavior. 1995; 8: 637-652. Disponível em: http://link.springer.com/article/10.1007\%2FBF01997235. Acesso em 15 janeiro 2015.

12 Chandra SBC, Hunt GJ, Cobey S, Smith BH. Quantitative trait loci associated with reversal learning and latent inhibition in honeybees (Apis mellifera). Behavior Genetics. 2001; 31: 275-285.

13 Ferguson HJ, Cobey S, Smith BH. Sensitivity to a change in reward is heritable in the honeybee, Apis mellifera. Animal Behavior. 2001; 61: 527-534. Disponível em: http://www.ncbi.nlm.nih.gov/pubmed/11699600. Acesso em 15 janeiro 2015.

14 Dinges, CW, Avalos A, Abramson CI, Craig DPA, Austin ZM, Varnon CA, Dal FN, Giray T, Wells H. Aversive conditioning in honey bees (Apis mellifera anatolica): A comparison of drones and workers. Journal of Experimental Biology. 2013; 216: 4124-4134. Disponível em: http://www.ncbi.nlm.nih.gov/pubmed/24133154. Acesso em 15 janeiro 2015.

15 Grozinger CM, Fan Y, Hoover SER, Winston ML. Genome-wide analysis reveals differences in brain gene expression patterns associated with caste and reproductive status in honey bees (Apis mellifera). Molecular Ecology. 2007; 16(22): 4837-4848. Disponível em: http://www.ncbi.nlm.nih.gov/pubmed/17927707. Acesso em 15 janeiro 2015.

16 Smith, AR, Seid MA, Jiménez and Wicsio WT. Socially induced brain development in a facultatively eusocial sweat bee Megalopta genalis (Halicitidae). Proceedings of the Royal Society B. 2010; 277: 21572163. Disponível em: http://www.ncbi.nlm.nih.gov/pubmed/20335213. Acesso em 15 janeiro 2015.

17 Smith BH, Menzel R. An analysis of variability in the feeding motor program of the honey bee: The role of learning in releasing a modal action pattern. Ethology. 1989; 82: 68-81. http://dx.doi.org/ 10.1111/j.14390310.1989.tb00488.x.

18 Bhagavan S, Smith BH. Olfactory conditioning in the honey bee, Apis mellifera: effects of odor intensity. Physiology and Behavior. 1997; 61(1): 107-117. Disponível em: http://www.ncbi.nlm.nih.gov/pubmed/8976540. Acesso em 15 janeiro 2015.

19 Smith BH. The olfactory memory of the honey bee Apis mellifera. I. Odorant modulation of short - and intermediate - term memory after single-trial conditioning. Journal of Experimental Biology. 1991; 161: 367-382. Disponível em: http://jeb.biologists.org/content/161/1/367.full.pdf+html. Acesso em 15 janeiro 2015.

20 Bhagavan S, Benatar S, Cobey S, Smith BH. Effect of genotype but not age or caste on olfactory learning performance in the honey bee, Apis mellifera. Animal Behaviour. 1994; 48: 1357-1369. http://dx.doi.org/10.1006\%2fanbe.1994.1372.

21 Abramson CI, Aquino IS, Stone SM. Failure to find proboscis conditioning in one-day old Africanized honey bees (Apis mellifera L.) and in adult Uruçu honey bees (Melipona scutellaris). International Journal of Comparative Psychology. 1999; 12: 242-262. Disponível em: https://escholarship.org/uc/item/5tj6f734.pdf Acesso em 15 janeiro 2015. 